\title{
Notas sobre las relaciones entre la Iglesia y el Gobierno del General Franco durante la Guerra Civil
}

\author{
NiEVES MONTESINOS SÁNCHEZ
}

«Las tensiones político sociales que se habían acumulado durante la II República y que habían bipolarizado a la sociedad española en dos grandes bloques antagónicos e irreconciliables abocaron a España a la guerra civil de 1936, con lo que el poder dominante, o sea, el vencedor en 1939, borró totalmente la legislación anterior e impuso la suya propia. Lo cierto es que desde un principio se presentó la contienda como Alzamiento Nacional y luego como Cruzada, lo que equivalía a recubrir la guerra civil, por parte de un bando, bajo el manto de la advocación divina, como si Dios, al igual que el pueblo hebreo de la antigüedad, le hubiera ordenado 'salir a la guerra contra los filisteos'.»'

Interesa destacar especialmente cómo se sucedieron los acontecimientos que llevarían a la implantación de un nuevo modelo de Estado que estaría vigente durante casi cuarenta años y que supuso un tratamiento y una visión muy peculiar de la cuestión religiosa y de las relaciones entre la Iglesia y el Estado.

"Como consecuencia del Alzamiento Nacional, el territorio español quedó dividido en dos zonas: una que continuaba sometida al régimen republicano; la otra bajo la autoridad del naciente Estado nacional.

Dos regímenes en lucha para lograr su extensión a toda España y dos regímenes con dos concepciones opuestas en punto a las relaciones entre la Iglesia y el Estado.» ${ }^{2}$

Lógicamente, en este momento volvemos a encontrarnos con problemas básicos en la historia política española y que aún estaban por 
resolver, a saber, sistema monárquico, sistema republicano; clericalismo o anticlericalismo; centralismo o regionalismo, y el conflicto siempre latente entre los propietarios y el proletariado.

Del mismo modo, en un principio, tanto en uno como en otro bloque vinieron a integrarse fuerzas a primera vista, en ocasiones francamente dispares, pero que resultaban unidas por su toma de posición ante los intereses en conflicto, ante las posturas iniciales de cada uno de los bloques.

Así, fue por todas estas circunstancias y por su trayectoria histórica fundamentalmente en la sociedad política española, por lo que la Iglesia se ve integrada ya desde los orígenes, en un bloque, en el nacional. En realidad, los intereses de la Iglesia se centraban en su oposición radical a la política republicana, aunque para ello se aliara a un sistema autoritario, pese a sus claras preferencias monárquicas. ${ }^{3}$

A reafirmar la integración inicial de la Iglesia en el bloque nacional, contribuyó la situación que se vivía en la zona republicana, ya que en esta se desarrolló una cruentísima persecución contra la Iglesia. ${ }^{4}$

Dicha persecución religiosa contó con la repulsa no sólo de la Iglesia Nacional, sino de la Iglesia en su conjunto, en especial en palabras del Romano Pontífice.

Por ello, cuando Pío XI recibió en Castelgandolfo a un numeroso grupo de evadidos de la zona roja, sus manifestaciones tendrían el siguiente tono: «... todo ha sido asaltado, arruinado, destruido con los modos más villanos y bárbaros, con el desenfreno más libertino, jamás visto, de fuerzas salvajes y crueles que pueden creerse imposibles, no digamos a la dignidad humana, sino hasta la misma naturaleza humana, aun la más miserable y la caída más abajo». ${ }^{5}$

Y en la Encíclica «Divini Redemptoris», también volvería a referirse a los acontecimientos acaecidos en la zona republicana con palabras similares: «... Destrucción tan espantosa se lleva a cabo con un odio, una barbarie y una ferocidad que no se hubiera creído posible en nuestro siglo». ${ }^{6}$ 
Pese a lo expuesto, resulta un hecho innegable que la situación en el pueblo vasco fue, si no diametralmente opuesta, su cuanto menos sustancialmente distinta a la vivida en el resto de las zonas republicanas. Por ello, y aunque excedería al objetivo prioritario de estas líneas efectuar un examen minucioso y contrastado del desarrollo de los acontecimientos en el pueblo vasco, sí que nos vemos en la obligación de apuntar, aún a sabiendas de lo controvertido que el tema continúa resultando, unas premisas muy generales que hicieron del vasco un tema diferente; a saber: 1) la incuestionable catolicidad del pueblo vasco; 2) la inclinación mayoritaria de los vascos por el bando republicano; 3) el carácter que tuvo el gobierno vasco de Euzkadi; 4) la Iglesia, en su conjunto, fue en términos generales más respetada que en las restantes zonas republicanas; 5) el clero, junto con el pueblo al que dirigía, se mostró partidario o, por los menos, no reaccionario ante el gobierno republicano. Todo ello trajo como consecuencia lo que pudieran ser denominadas «represalias» por parte del gobierno nacional, y entre ellas merecen destacarse la expulsión del obispo de Victoria, Monseñor Múgi$\mathrm{ca}$, y el fusilamiento de sacerdotes. ${ }^{?}$

$\mathrm{Si}$, como expusimos, la integración inicial de la Iglesia al bando nacional, excepción hecha del pueblo vasco, fue clara en un principio, ya que iniciada la guerra civil la postura de la Iglesia y de las partes venían dadas en función del pasado de la sociedad y la política española; ${ }^{8}$ esta afirmación puede ser corroborada con algunos datos y documentos especialmente significativos que se sucederían desde los primeros momentos de la contienda.

En primer lugar, la jerarquía eclesiástica si bien no participó directamente en el Alzamiento Nacional, ${ }^{9}$ sí que lo consideró como un movimiento libertador. Quizá por ello sus documentos tanto individuales como colectivo representan una apología del nuevo régimen, que se fundamenta básicamente no en unas convicciones políticas, sino en la lucha contra un enemigo común (la república, el comunismo), y especialmente en el carácter religioso que se le otorga a la guerra por la jerarquía eclesiástica española, de forma unilateral. ${ }^{10}$

Abundan y aclaran esta idea numerosos y valiosos documentos. Entre ellos podemos destacar: la llamada Pastoral conjunta de los obispos vas- 
cos, efectuada ya el 6 de agosto de 1936 y varias declaraciones de miembros de la jerarquía eclesiástica, como las de Monseñor Olaechea de Pamplona; del arzobispo de Valladolid; del arzobispo de Granada, etc. ${ }^{11}$ En todos estos textos aparecen unidas las ideas de religión y patria, y el carácter de cruzada de la guerra civil.

Especial mención merecen entre las primeras manifestaciones y actitudes eclesiásticas dos documentos por la repercusión que tuvieron. Nos referimos a la Pastoral de Monseñor Pla y Daniel, arzobispo de Salamanca y a la del Cardenal Gomá.

Monseñor Pla y Daniel, en su Pastoral «Las dos ciudades», diría que no se puede criticar a la Iglesia "porque se haya abierta y oficialmente pronunciado a favor del orden contra la anarquía, a favor de la implantación de un gobierno jerárquico contra el disolvente comunismo, a favor de la defensa de la civilización cristiana y sus fundamentos, religión, patria y familia, contra los sin Dios, sin patria y hospicianos del mundo, en frase feliz de un poeta cristiano». ${ }^{12}$

Por su parte, el Cardenal Gomá, que apoyó decididamente el movimiento desde el primer día; en su pastoral «El caso de España» vendría a firmar: «Esta cruelísima guerra es en el fondo una guerra de principios, de doctrinas, de un concepto de la vida y del hecho social contra otro, de una civilización contra otra. Es la guerra que sostiene el espíritu cristiano y español contra este otro espíritu». ${ }^{13}$

Queda claro, en consecuencia, el apoyo de la Iglesia al alzamiento, el rechazo de la república y el comunismo, y el contenido esencialmente religioso, por encima del social o político que la jerarquía atribuye a la guerra, con lo que su apoyo al nuevo régimen queda, en principio, justificado.

En segundo lugar, hay que traer a colación un dato nuevo. Frente a la actitud de la jerarquía que, como quedó expuesto, no participó directamente en el Alzamiento, resulta indiscutible la participación de los católicos en la sublevación militar del 18 de julio de 1936. En efecto, los requetés constituyen la aportación militar decisiva de los católicos, y presentaron un apoyo cualificado tanto para el General Mola como 
para la Junta de Generales y posteriormente para Franco. ${ }^{14}$ Aun así, y teniendo presente también la colaboración, aunque no armada, de numerosas personalidades católicas, ${ }^{15}$ resultó mucho más relevante el apoyo moral de los católicos a la sublevación, ya que de manera semejante a su jerarquía, consideran a los alzados en buena medida como sus salvadores.

$\mathrm{Y}$, en tercer lugar, debemos establecer una matización importante para conocer desde dónde surgieron los apoyos que serían utilizados para configurar el nuevo régimen y, por ende, el nuevo Estado. Tal matización, si bien ya fue enunciado anteriormente «el carácter religioso que se le otorgó a la guerra por la jerarquía española de forma unilateral», precisa un posterior desarrollo. Es más, conocemos cuál fue la postura inicial de la Iglesia, pero no la de los alzados.

Payne afirma que «se proponían instaurar un régimen más autoritario y conservador, dominado por los militares. La religión no tuvo ningún papel oficial en esa empresa. Algunos de los activistas militares no sentían ningún interés por la defensa del catolicismo, mientras que otros se mostraban renuentes a complicar aún más la situación dando a su movimiento un tono religioso. Los rebeldes esperaban un apoyo extenso de las clases medias y no deseaban provocar el antagonismo de los anticlericales moderados. Por eso, sus primeras declaraciones, en los comienzos del conflicto, no hicieron ninguna referencia a la cuestión religiosa». ${ }^{24}$

En efecto, la importancia del tema o factor religioso no fue tomada en consideración originariamente. Por lo tanto, ni los jefes insurrectos ni $\mathrm{Franco}^{17}$ se consideran, en un principio, como cruzados, sino más bien como defensores del orden republicano.

Avalan esta tesis las afirmaciones efectuadas por Franco cuando lanza el primer manifiesto de la sublevación militar, o posteriormente el 22 de julio. ${ }^{18} \mathrm{Y}$ también podrían utilizarse otros argumentos como la composición de la Junta de Defensa Nacional o su programa. ${ }^{19}$

El General Franco, en el discurso que pronuncia el 1 de octubre, con ocasión de su elevación a la Jefatura del Estado, se referiría a la problemática religiosa en los siguientes términos: «El Estado, sin ser confe- 
sional, concordará con la Iglesia Católica, respetando la tradición nacional y el sentimiento religioso de la inmensa mayoría de los españoles, sin que ello signifique intromisión ni reste libertad para la dirección de las funciones específicas del Estado». ${ }^{20}$

Ahora bien, tergiversaríamos el desarrollo de los acontecimientos si no advirtiéramos que, en algunos pronunciamientos militares, el tema religioso sí apareció expresamente mencionado, ${ }^{21}$ quizá porque la dirección militar decidiese aprovechar el apoyo católico que se le brindaba, quizá por circunstancias diversas; pero ello no significó que se convirtiera en el motivo fundamental de la guerra.

Será por todo ello, por lo que nos manifestamos partidarios de que en el controvertido tema de la «Cruzada», fueron los obispos y no Franco quienes utilizaron por primera vez la idea de cruzada como interpretación ideológica de la guerra civil. De este modo, el factor religioso se incorporará a la ideología política de Franco durante la guerra civil y por efecto de la guerra civil; de ahí se derivará que, siendo el último elemento de su ideología, acabe por transfigurarla de raíz y con un sentido permanente. ${ }^{22 / 23}$

Es más, si el trasfondo religioso como justificación y legitimación de la guerra, tiene su máximo sentido en la interpretación que a tal efecto efectúa la jerarquía eclesiástica; una vez utilizado por la Iglesia, y a la vista de las ventajas que de él pudieran derivarse a nivel nacional e internacional (aunque tampoco hay que olvidar los posibles inconvenientes), comienza a ser utilizado por el nuevo estado pero con menor intensidad. Incluso Franco daría claras pruebas de que la fe y el nacionalismo debían ir unidos decantándose a favor de la ideología tradicional española. ${ }^{24}$

Si hasta el momento hemos hecho referencia a los apoyos iniciales de la Iglesia, resulta preciso que nos detengamos en un documento que expresa, resume y manifiesta de manera evidente el apoyo de la Iglesia, por boca de su jerarquía, al nuevo sistema político: la Carta colectiva del Episcopado español. ${ }^{25}$

Dada la extensión del documento, ofrecemos una síntesis del mismo que consta de cuatro conclusiones: 
«1. ${ }^{\circ} \quad$ Que la Iglesia, a pesar de su espíritu de paz y de no haber querido la guerra ni haber colaborado en ella, no podía ser indiferente en la lucha: se lo impedían su doctrina y su espíritu, el sentido de conservación y la experiencia de Rusia. De una parte se suprimía a Dios, cuya obra ha de realizar la Iglesia en el mundo, y se causaba a la misma un daño inmenso, en personas, cosas y derecho, como tal vez no lo haya sufrido institución alguna en la historia; de la otra, cualesquiera que fuesen los humanos defectos, estaba el esfuerzo por la conservación del viejo espíritu español y cristiano.

$2 .^{\circ}$ La Iglesia, con ello, no ha podido hacerse solidaria de conductas, tendencias o intenciones que, en el presente o en el porvenir, pudieran desnaturalizar la noble fisonomía del movimiento nacional, en su origen, manifestaciones y fines.

$3 .^{\circ}$ Afirmamos que el levantamiento cívico-militar ha tenido en el fondo de la conciencia popular un doble arraigo: el del sentido patriótico, que ha visto en él la única manera de levantar a España y evitar su ruina denifitiva; y en el sentido religioso, que lo consideró como la fuerza que debía reducir a la impotencia a los enemigos de Dios y como la garantía de la continuidad de su fe y de la práctica de su religión.

$4 .^{\circ}$ Hoy por hoy, no hay en España más esperanza para reconquistar la justicia y la paz y los bienes que de ellas se derivan que el triunfo del movimiento nacional. Tal vez hoy menos que en los comienzos de la guerra, porque el bando contrario, a pesar de todos los esfuerzos de sus hombres de gobierno, no ofrece garantías de estabilidad política y social». ${ }^{26}$

Podemos establecer una serie de consideraciones acerca del contenido, finalidad y repercusión de tan importante Carta colectiva.

Ante todo, hay que destacar que estamos ante un documento mucho más ponderado de los que hasta ahora hemos traído a cólación. Probablemente pueda ser esta la razón de que, aunque el espíritu del contenido del texto puede identificarse con el término, en ningún momento aparece en la citada Carta colectiva el término "Cruzada» tan usado hasta esta fecha, en contra de lo que en ocasiones se ha dicho.

La Carta es obra del Cardenal Gomá, el cual, como conocemos, se había pronunciado ya de forma reiterada sobre la situación de la gue$\operatorname{rra}^{27}$

En la gestación de la misma confluyen varias circunstancias y acontecimientos. ${ }^{28}$ Entre ellos, la idea de la Santa Sede de un nuevo docu- 
mento episcopal, de una verdadera pastoral auténticamente colectiva que viniese a eliminar la penosa impresión de la pastoral de los obispos vascos; la del Cardenal Gomá, de hacer un documento colectivo que paliara en parte la falta de una declaración de la Santa Sede en apoyo del Gobierno de Burgos; el deseo que el General Franco expresaría a Gomá acerca de la necesidad de un documento colectivo del Episcopado español con el fin de desvirtuar la información falsa o tendenciosa que tanto daño había hecho al nombre de España y de la Iglesia española; y, la opinión mayoritaria de los metropolitanos acerca de la oportunidad del escrito, excepción hecha del Cardenal Vidal i Barraquer. ${ }^{29}$

También, lógicamente, la Carta recoge y corrobora los postulados básicos en los que fundamenta su apoyo al nuevo régimen y por los que se integra en uno de los dos bandos. La oposición al comunismo y la motivación religiosa.

Además, aunque se reitera el apoyo moral al nuevo régimen, éste se argumenta también sobre la base de lo que de él se espera, y de lo que en el futuro debería y no debería llegar a ser.

Podríamos concluir el análisis de la Carta dejando constancia de que en consonancia con los propósitos con que había sido pensada, su difusión fue muy extensa, y debió gozar a determinados niveles del esperado éxito, ${ }^{30}$ pese a que no se conoce a ciencia cierta la opinión o parecer del vaticano sobre la misma. ${ }^{31}$

En suma, esta pastoral significa el cumplimiento de la empresa legitimadora de la sublevación por parte de la Iglesia de España, pero, también sirve para revelar las divisiones que la sacralización de la guerra civil comienzan a provocar entre los católicos (especialmente significativas fueron las actuaciones de Vidal i Barraquer y Múgica).

Si tras la difusión del todavía hoy polémico documento el horizonte se despejaba cada vez más para el triunfo de la España nacionalista, y si gracias al mismo la sublevación militar de Franco empezó a verse con otros ojos en el mundo, en virtud del decidido apoyo de la Iglesia española, cuyo compromiso con una de las partes unció a la institución eclesiástica al carro del franquismo durante varias décadas; ${ }^{32}$ para com- 
pletar la visión general del tema deberemos conocer si la Iglesia a nivel internacional, el Vaticano, asumía la misma postura que la Iglesia española. Nuestro objetivo, pues, radica en averiguar cuáles fueron las relaciones del Vaticano con los bandos en los que España se encontraba dividida. ${ }^{33}$

Las relaciones de la Santa Sede con el gobierno republicano y con el gobierno de Burgos se desarrollaron por caminos distintos y corrieron suertes diversas, dadas entre otras circunstancias, las preferencias o simpatías iniciales del Vaticano hacia el Movimiento Nacional, lo que no impidió que fuera extremadamente cauteloso a la hora de realizar un reconocimiento formal en favor del mismo.

Por lo que atañe a las relaciones de la Santa Sede con el gobierno republicano, puede afirmarse que éstas no se vieron formalmente interrumpidas ni por la sublevación militar ni por la persecución religiosa que se desencadenó en la zona roja.

Al producirse el alzamiento, Luis de Zulueta, que había sido nombrado embajador de España en el Vaticano el 1 de junio de 1936, permanecerá en su puesto hasta agosto del mismo año, y en ningún momento se le retira el placet. ${ }^{34}$

El Nuncio Tedeschini abandona la sede española el 11 de junio de 1936, al ser nombrado cardenal, y su sucesor, Monseñor Cortieri, no llega a tomar posesión de su cargo. A partir de este momento, la Nunciatura, que permanece abierta, está bajo la dirección de Monseñor Silvio Sericano y, posteriormente, de un secretario, Alfonso Ariz Echarte, siendo considerada por algunos observadores su existencia como oficiosa. ${ }^{35}$

Pese a todo y como la Santa Sede no consideró que existiera una causa de ruptura jurídica aunque el gobierno republicano no atendiese sus notas de protesta, hubo diversos intentos para normalizar las relaciones. Resultaron relevantes las actuaciones tanto de Irujo como de católicos vascos y catalanes.

Observamos que los intentos de normalización resultaron infructuosos, aun a sabiendas de los beneficios innegables que podía reportar la 
reanudación de relaciones entre el gobierno republicano y la Santa Sede. Sin duda contribuyó, amén de la trayectoria republicana, las relaciones oficiosas que se mantenían con el gobierno del General Franco.

Ahora bien, ¿cuáles eran entre tanto esas relaciones? Podemos establecer una aseveración inicial; las relaciones entre la Santa Sede y el gobierno del General Franco transcurrieron por cauces sustancialmente diferentes, hasta llegar al reconocimiento oficial del Gobierno Nacional.

Desde los primeros momentos del alzamiento, la Santa Sede recibiría información puntual de los acontecimientos por medio del Cardenal Gomá. Por ello existe constancia de diversos informes enviados a Roma ya desde agosto de $1936,{ }^{36}$ en los que el Cardenal Gomá (que recordemos, había apoyado públicamente el alzamiento casi desde sus orígenes) insistiría en la situación de amplia libertad y aun de favor y protección, de que podría gozar la Iglesia de triunfar el movimiento nacional; en las manifestaciones públicas de religiosidad; y en la reviviscencia de la fe y la piedad cristiana como consecuencia de la situación creada por la guerra.

Gracias a la habilidad personal del Cardenal Gomá los primeros conflictos, que no se hicieron esperar (baste citar el discurso pronunciado por el General Franco con ocasión de su elevación a la Jefatura del Estado; la expulsión del obispo de Vitoria, Monseñor Múgica; o el fusilamiento de sacerdotes vascos) no llegaron a producir las consecuencias que hubieran sido previsibles, dado el malestar que los acontecimientos habían provocado en el Vaticano.

Quizá por todo ello, y a la vista de los distintos informes presentados en Roma personalmente por Gomá, se llegaría a la conclusión de que era necesaria alguna forma de reconocimiento del gobierno de Burgos, pero como no se quería hacer un reconocimiento formal, se arbitró la solución intermedia de enviar un representante confidencial a modo de Legado Pontificio. El representante confidencial sería el Cardenal Gomá.

El Cardenal se trajo de Roma dos cartas del Cardenal Pacelli y una bendición especial del Papa Pío XI al «General Franco y a cuantos con 
él colaboraron en la defensa del honor de Dios y en la defensa de España». Una de las cartas contenía las credenciales para entregárselas al General Franco, y en la segunda había instrucciones para no permitir la sujeción de la Iglesia al poder civil, así como temas puntuales en los que se consideraba necesario hacer hincapié. ${ }^{37}$

A su llegada a España el Cardenal Gomá se entrevistaría con el General Franco, y hay que destacar que de esta entrevista ya saldrían algunos acuerdos. ${ }^{38}$

Pero los conflictos no cesaron, y si bien en este momento eran lógicos por cuanto se empezaba a intentar dar forma a lo que habrían de ser las relaciones entre ambos poderes, también continuarían posteriormente.

Primeramente se centrarían en las negociaciones para la regulación del ejercicio de los sacerdotes castrenses, ya que la restauración de la jurisdicción castrense fue efectuada unilateralmente por el Estado. Fue el General Germán Gil Yuste quien, mediante una Orden de la Secretaría de Guerra, reguló, provisionalmente, la reorganización de las Tenencias Vicarías Castrenses. La Orden se hizo extensiva a la Marina. ${ }^{39}$

Tales acontecimientos provocaron las protestas de la Santa Sede, y el que ésta advirtiera de los peligros que podían derivarse de tales formas de hacer, que quizá fueran utilizadas por el Estado para entrar a legislar en materías eclesiásticas.

Aun así, el Cardenal Gomá, consciente de los continuos roces que se sucedían, permanecía fiel a su posición y convicciones, insistiendo ante Roma para que se llegara al reconocimiento del Gobierno Nacional, haciendo ver los beneficios que de ello se derivarían, especialmente para la Iglesia nacional, y haciéndose eco de las palabras e inquietudes del General Franco en este sentido, ya que sin el reconocimiento le faltaba a su empresa un apoyo moral insustituible.

La Santa Sede, entre tanto, seguía mostrándose extremadamente cautelosa en el tema. Del reconocimiento podrían derivársele posibles resonancias y efectos negativos, le hubiera supuesto tomar partido por el bloque de Italia y Alemania y, previsiblemente, empeorar las relacio- 
nes que se mantenían con países como Estados Unidos, Francia o Inglaterra. Además, hay que dejar constancia de que los intereses de la Iglesia Vaticana no siempre coinciden con los de las Iglesias establecidas en las diferentes sociedades nacionales. ${ }^{40}$

El desárrollo de los acontecimientos nos obliga a poner de manifiesto que, aunque con prudencia, se iban dando los pasos necesarios por ambas instancias que culminarían en el reconocimiento definitivo.

Mientras que el Cardenal Pacelli envía a España, en principio sin ninguna misión diplomática oficial, a Monseñor Hildebrando Antoniutti, ${ }^{41}$ cuya tarea consiste en ocuparse de los niños vascos y confidencialmente en estudiar sobre el terreno e informar a Roma de las posibilidades de llevar a cabo el reconocimiento; el gobierno nombró al Marqués de Aycinena, Pablo Churruca, ministro plenipotenciario con la finalidad de evitar los enfrentamientos radicales con la Santa Sede que venían produciéndose con su predecesor, el Marqués de Magaz.

Finalmente, el 7 de septiembre de 1937, el Cardenal Pacelli comunicaría al Cardenal Gomá el nombramiento de Monseñor Antoniutti como encargado de negocios de la Santa Sede en España. Dada la satisfacción ante tal nombramiento por parte del Gobierno, que lo interpretó como un reconocimiento, se le dispensaron toda clase de honores. ${ }^{42}$

Uno de los primeros asuntos que reclamó la atención de Monseñor Antoniutti fue la existencia de numerosas sedes vacantes, las cuales necesitaban ser ocupadas tras los oportunos nombramientos.

Diversos problemas confluían en este tema, fundamentalmente el del procedimiento a utilizar, ya que la Santa Sede consideraba en base a las tesis sustentadas por el Papa Benedicto XV, que el Concordato de 1851 no podía ser aplicado, ya que podría ser considerado como caducado e inexistente en el momento actual. ${ }^{43}$

La solución por la que se optó fue la de utilizar una «fórmula de cortesía» en los traslados que primeramente se efectuaron, comunicando al encargado de negocios en la Santa Sede las designaciones que venían haciéndose, mediante un emisario de la Secretaría de Estado, 48 horas antes de la publicación del nombramiento en el periódico Vaticano. 
El Encargado de Negocios ante la Santa Sede advirtió de que el procedimiento podía no ser correcto. Y el asunto se complicó cuando la Santa Sede, de manera unilateral, nombró como obispo de León al P. Carmelo Ballester, actuación a la que el gobierno del General Franco respondió de manera inmediata dando instrucciones al Marqués de Aycinena para que protestase por el nombramiento, que sería aceptado sólo en cuanto se trataba de un hecho consumado.

A partir de este suceso, quizá evitable, se iniciaron las negociaciones que culminaron con la firma del Acuerdo de 1941. Dicho Acuerdo será una pieza clave en el desarrollo de las relaciones Iglesia-Estado en España. ${ }^{44}$

Nos resta todavía referirnos a dos nombramientos de suma trascendencia. Los nombramientos son los de Gaetano Cicognani y José Yanguas Messía.

Por fin se conseguiría el tan deseado reconocimiento vaticano, tal vez porque la situación en ese momento era más propicio. Hay que decir que a ello contribuyó el hecho de que el Gobierno del General Franco se había encargado de crear un clima más distendido, gracias por ejemplo a determinadas declaraciones de intenciones con proyección católica y a la derogación de algunas leyes republicanas contrarias a los intereses eclesiásticos. ${ }^{45}$

La designación de Monseñor Cicognani se hizo pública el 16 de mayo de 1938, el cual llega a San Sebastián el 19 de junio y presenta sus cartas credenciales el día 24. Seis días más tarde, José Yanguas Messía reemplaza al encargado de negocios Churruca como embajador español ante el Vaticano. «Este intercambio de diplomáticos rubrica el reconocimiento de pleno derecho del Estado Nacional, veintidós meses después del comienzo de la guerra, cuando el gobierno de Burgos ha sido ya reconocido, de facto o de iure por catorce Estados» ${ }^{46}$

El General Franco al recibir oficialmente al Nuncio Cicognani le dijo: «Excelencia Reverendísima, podeis decir al Santo Padre que no es España ni verdaderos españoles los que obedeciendo consignas extranjeras, quemaron los templos del Señor, martirizaron a sus ministros y 
destruyeron implacablemente, con saña sin ejemplo, todo lo que en nuestra patria significaba, al mismo tiempo que manifestación de cultura, expresión de fe católica». ${ }^{47}$

Aceptar el planteamiento vertido en el texto transcrito llevaba consigo, suponía, un peligro importante; el identificar ser buen español con una línea política y una actuación religiosa determinada. Consecuentemente la identificación de la Iglesia con el régimen político surgiría de manera espontánea, de modo que lo nacional sería igual a catolicismo, tradicionalismo, autoridad, orden, etc., rechazándose, por tanto, valores que se consideraban opuestos como la democracia, la libertad o la república. ${ }^{48}$

El embajador Yanguas Messía en la presentación de cartas credenciales pronunció un discurso en el que reiteró la catolicidad de España, que había sido sellada con el sacrificio y afirmada solemnemente en su Cruzada, e hizo especial mención a las disposiciones del Gobierno en materia religiosa.

El discurso fue contestado por el Papa Pío $\mathrm{XI}^{49}$ y en él, aunque de forma improvisada, se vertieron importantes afirmaciones que vaciarían de contenido y significado las matizaciones establecidas a priori por la diplomacia vaticana.

Dada la sutileza que caracteriza a la diplomacia vaticana, al entregársele a Monseñor Cicognani sus cartas credenciales se le dijo que iba como Nuncio cerca del gobierno de Burgos, y del mismo modo, cuando el embajador Yanguas recibe la comunicación de la Secretaría de Estado en la que se le indica la fecha en que iba a ser recibido por su Santidad para la entrega de las cartas credenciales, se le dirige como «Embajador Extraordinario y Plenipotenciario de la España Nacional cerca de la Santa Sede». ${ }^{50}$

En consecuencia, cuando el Papa en su discurso pronunció frases como «a la España entera que vos representais» o «Franco, jefe actual de España» o "a fin de que pueda trabajar cada vez con mayor fruto para el bien de vuestra y nuestra querida España», dejan de tener sentido todas las matizaciones establecidas. 
Algunos observadores han señalado que el Vaticano reconoció al Gobierno Nacional porque veía como segura la victoria del General Franco. Nosotros, después de recorrer el complejo entramado por el que discurrían las relaciones entre la Santa Sede y el Gobierno de Burgos no podemos ni debemos sumarnos a una argumentación tan simplista, ya que el reconocimiento fue consecuencia, por lo menos, de los múltiples factores apuntados.

Progresivamente, en su formulación externa, en sus manifestaciones públicas, la proximidad entre el régimen del General Franco y la Iglesia se fue haciendo cada vez más evidente. Por ello consideramos que, al ser imposible para el poder civil y militar asumir por sí solo la tarea de propaganda contrarrevolucionaria, la aportación y colaboración de la Iglesia se convertirá en decisiva, consistiendo fundamentalmente en la matización religiosa y cristiana que impregnará toda la sociedad española. «El Nuevo Estado se congraciaba con la Iglesia a través de su política restauracionista en el campo religioso y simultáneamente iba definiéndose en todos sus actos como católico. Lo católico representaba la construcción ideológica dominante en el conjunto de la instancia ideológica»..$^{51}$

En efecto, el nuevo régimen, para congraciarse con la Iglesia tanto nacional como con la Santa Sede, fue dictando una serie de normas tendentes a restablecer la situación de la que se disfrutaba con anterioridad al advenimiento de la II República. Externamente se daban muestras de clara simpatía y entendimiento, aunque internamente las tensiones existían y eran debidas a las negociaciones para el establecimiento de un acuerdo o de un nuevo concordato.

La muerte del Papa Pío XI y su sucesión por Pío XII tampoco supuso la existencia de conflictos que merezcan una especial atención.

Terminada la guerra, en el tema que nos ocupa, serán especialmente relevantes los telegramas que se cruzaron entre el Papa y Franco.

Su Santidad el Papa Pío XII dirigió al Generalísimo Franco el siguiente telegrama: «Levantando nuestro corazón al Señor, agradecemos sinceramente, con V.E., deseada victoria católica España. Hace- 
mos votos para que este queridísimo país, alcanzada la paz, emprenda con nuevo vigor sus antiguas y cristianas tradiciones, que tan grande le hicieron. Largos sentimientos efusivamente envíamos a Vuestra Excelencia, y a todo el noble pueblo español nuestra apostólica bendición». ${ }^{52}$ El Papa también tuvo palabras para todos los españoles y para los obispos. ${ }^{53}$

El Generalísimo Franco contestó el telegrama de Pío XII con el siguiente: «Interna emoción me ha producido paternal telegrama de Vuestra Santidad con motivo victoria total de nuestras armas que en heróica cruzada han luchado contra enemigos de la Religión, de la Patria y de la civilización cristiana. El pueblo español que tanto ha sufrido, eleva también con Vuestra Santidad, su corazón al Señor, que le dispensó su Gracia, y le pide protección para su gran obra del porvenir, y conmigo expresa a Vuestra Santidad inmensa gratitud por sus amorosas frases y por su apostólica bendición, que ha recibido con religioso fervor $y$ con la mayor devoción hacia Vuestra Santidad». ${ }^{54}$

Aunque los discursos y mensajes son siempre grandilocuentes también son, en este caso, significativos del clima de felicidad reinante. ${ }^{55}$ Las tensiones han desaparecido, al menos momentáneamente, ya que aflorarán de nuevo en etapas inmediatamente posteriores.

Vislumbradas someramente cuáles fueron las relaciones primeras entre la Iglesia y el Nuevo Régimen, podemos apuntar a modo de conclusiones las siguientes:

1) La motivación ideológica de la contienda, que en los primeros momentos es utilizada por la jerarquía eclesiástica nacional como elemento legitimador del apoyo que presta al régimen, se convierte posteriormente en argumentación de suma utilidad para el propio régimen y, en especial para Franco. Servirá como tarjeta de presentación en las relaciones con la Iglesia a nivel internacional y en las relaciones internacionales en general, aunque en este último caso con muy diversos resultados.

2) El Vaticano apuesta por el nuevo régimen en función de las esperanzas puestas en el mismo en orden a la restauración de los principios tradicionales católicos en la nueva España, de lo que quiso ver buena 
prueba en las actitudes tanto de Franco como de las personas más representativas del régimen.

3) La Iglesia española y en especial su jerarquía, seguirá en líneas generales las pautas marcadas por la Iglesia romana, rara vez innovadora. ${ }^{56}$

4) Producida la victoria de la contrarrevolución franquista y nacionalcatólica, las demandas efectuadas por la Iglesia al Estado van a variar sustancialmente. La victoria colocará a la Iglesia en una nueva posición que la llevará a buscar metas más ambiciosas, entre ellas intentará reconquistar el espacio sociopolítico, imponer la confesionalización tanto del Estado como de diversas instituciones sociales secularizadas y, por supuesto, recristianizar al pueblo. ${ }^{57}$

5) El Estado, al intentar ofrecer un marco y un contenido ideológico para conseguir la adhesión al régimen, delegará su papel de tutor ideológico en la Iglesia fundamentalmente, frente a los elementos que se sitúan en la vertiente tradicionalista y religiosa de la sociedad. El Estado tratará de utilizar el aparato católico para los fines del poder contrarrevolucionario, de modo que el nacionalcatolicismo prevalezca sobre el fascismo. ${ }^{58}$

Predecir quién, en esta confrontación aparentemente amistosa de poderes saldrá ganando, si es que así fue, supondría adentrarnos en el estudio de las relaciones entre la Iglesia y el Estado durante los casi cuarenta años de pervivencia del régimen franquista, y ello obviamente escapa al objetivo del presente trabajo. Apuntemos, no obstante, que la indeterminación inicial de los sistemas eclesial y político, así como las actuaciones, en ocasiones excesivamente politizadas de la jerarquía eclesiástica española depararán no pocos inconvenientes en el porvenir más inmediato de las relaciones entre ambos poderes. 


\section{N O T A S :}

1. Vid. D. BASTERRA, El derecho a la libertad religiosa y su tutela jurídica (Madrid, 1989), 221.

2. Vid. I. MARTIN MARTÍNEZ, «El desarrollo de la Iglesia Española y sus relaciones con el Estado», El Nuevo Estado español, 2. ${ }^{\mathrm{a}}$ ed. (Madrid, 1963).

3. Cfr. J.J. RUIZ RICO, El papel político de la Iglesia Católica en la España de Franco (Madrid, 1977), 17-20.

4. A. MONTERO, Historia de la persecución religiosa en España, 1936-1939 (Madrid, 1961). Guía de la Iglesia en España (Madrid, 1954).

La denominación roja en España (Madrid, 1953).

5. «Palabras del Papa Pío XII a los Obispos, Sacerdotes, Religiosos y Seglares prófugos de España», el 14 de septiembre de 1936.

6. Encíclicas y Documentos Pontificios (Madrid, 1955). Divini Redemptoris 20.

7. Señalar también que resultó especialmente discutida y controvertida por su repercusión en el clero que no la acogió favorablemente, la Instrucción pastoral que el 6 de agosto de 1936 publican conjuntamente los obispos de Vitoria y de Pamplona. Vid. A. MONTERO, op. cit., 682.

8. Cfr. J.J. RUIZ RICO, op. cit., 16.

9. Se puede contrastar esta opinión en GUY HERMET, Los católicos en la España Franquista II. Crónica de una dictadura (Madrid, 1986), 30.

10. Cfr. P. LOMBARDÍA, La Actitud de la Iglesia ante el Franquismo, Iglesia Católica y regímenes autoritarios y democráticos (Madrid, 1987), 85.

11. Pueden consultarse las siguientes obras: J. CHAO REGO, La Iglesia en el franquismo (Madrid, 1976); A. GRANADOS, El Cardenal Gomá (Madrid, 1958); M.L. RODRÍGUEZ AISA, El Cardenal Gomá y la guerra de España. Aspectos de la gestión pública del Primado 1936-1939 (Madrid, 1981); L. SUÁREZ FERNÁNDEZ, Franco y su tiempo, vol. II (Madrid, 1985).

12. Vid. A. MONTERO, op. cit., 688-708.

13. Vid. I. GOMÁ Y TOMÁS, Pastorales de la guerra de España (Madrid, 1955).

14. Cfr. GUY HERMET, op. cit., 29.

15. Cfr. J. TUSELL, Franco y los católicos (Madrid, 1984), 17 ss.

16. Vid. STANLEY G. PAYNE, El catolicismo español (Barcelona, 1984), 218.

17. En lo que concierne a la trayectoria religiosa y católica de Franco hemos encontrado datos relevantes en: R. DE LA CIERVA, Francisco Franco. Un siglo de historia (Madrid, 1973); 
ídem. Historia del Franquismo. Orígenes y configuración (Barcelona, 1976); J.P. FUSI, «Fanco» (Madrid, 1985).

18. Vid. F. DÍAZ-PLAJA, La guerra de España en sus documentos (Madrid, 1986), 24.

19. Ídem., 24-26.

20. Vid. L. SUÁREZ FERNÁNDEZ, op. cit., 89-116.

21. Algunos pronunciamientos del General Mola en el sentido indicado pueden encontrarse en:M. TUÑóN DE LARA, El hecho religioso en España (París, 1968), 135 y en F. DÍAZPLAJA, op. cit., 57-59.

22. Cfr. R. DE LA CIERVA, Historia del Franquismo. Orígenes y configuración 1939-1945 (Barcelona, 1976), 104. Y también J.M. CUENCA TORIBIO, Relaciones Iglesia-Estado en la España contemporánea (1833-1983) (Madrid, 1983), 71.

23. En el tema de la Cruzada, merecen destacarse además de las obras ya citadas: F. G. OLMEDO, El sentido de la guerra española (Bilbao, 1938); J. M. GARCÍA ESCUDERO, Historia política de las dos Españas (Madrid, 1976); A. DE CASTRO ALBARRAN, Guerra Santa.El sentido católico de la guerra española (Burgos, 1938); J. DE LA CRUZ MARTÍNEZ, ¿Cruzada o rebelión? (Zaragoza, 1938).

24. Vid. las obras ya citadas de STANLEY G. PAYNE y F. DÍAZ-PLAJA.

25. Vid. Documentos Colectivos del Episcopado español, 1870-1974. BAC (Madrid, 1974), 219-242.

26. Vid. F. GIL DELGADO, Conflicto Iglesia-Estado. España, 1808-1975 (Madrid, 1975), 170.

27. Vid. I. GOMA Y TOMÁS, Pastorales de la guerra de España (Madrid, 1955).

28. Vid. A. GRANADOS, El Cardenal Gomá (Madrid, 1958).

29. Vid. A. GRANADOS, op. cit., 172; J.J. RUIZ RICO, op. cit., 50-51; GUY HERMET, op. cit., 46-48; S. G. PAYNE, op. cit., 229-221; L. SUÁREZ FERNÁNDEZ, op. cit., vol. II, 236-237.

30. Cfr. J.J. RUIZ RICO, op. cit., 53.

31. Cfr. GUY HERMET, op. cit., vol. II, 49-50.

32. Cfr. J.L. ABELLÁN, De la guerra civil al exilio republicano (1936-1977) (Madrid), 58.

33. En el tema de las relaciones diplomáticas merece destacarse la obra de A. MARQUINA BARRIO, La diplomacia vaticana y la España de Franco (1936-1945) (Madrid, 1983).

34. Cfr. CHARLES-ROUX, Huit ans au Vatican (París, 1947), 180.

35. V. PALACIO ATARD, Cinco historias de la república y de la guerra (Madrid, 1973), 83.

36. Los informes pertenecen al Archivo del Cardenal Gomá y pueden consultarse en A. MARQUINA BARRIO, op. cit., 44 ss.

37. Archivo del Cardenal Gomá. Carta al General Franco de 22 de diciembre de 1936. 
38. Vid. A. MARQUINA BARRIO, op. cit., 53.

39. Vid. Orden de la Secretaría de Guerra de organización de las Tenencias Vicarias Castrenses de 31 de diciembre de 1936 y Orden de 11 de enero de 1937 por la que se hacía extensiva su aplicación a la Marina.

40. En cuanto a las razones que forzaban a la Santa Sede a guardar una especial prudencia, vid J.J. RUIZ RICO, op. cit., 58-59.

41. Diversas fuentes consultadas señalan que cuando Monseñor Hildebrando Antoniutti llega a España el 25 de julio de 1937 lo hace en calidad de Encargado de Negocios de la Santa Sede, pero este nombramiento no sería efectuado sino meses después.

42. Cfr. A. MARQUINA, op. cit., 66.

43. Ídem., 86.

44. Vid. C. CORRAL, Acuerdos Iglesia-Estado.

45. Vid. A. BERNÁRDEZ CANTON, Legislación eclesiásticas del Estado (Madrid, 1965).

46. Vid. GUY HERMET, op. cit., vol. II, 97.

47. Vid. Iglesia, Estado y Movimiento Nacional (Madrid, 1963), 32.

48. Cfr. J. M. LABOA, Iglesia y Religión en las Constituciones españolas (Madrid, 1981 ), 74.

49. Vid. A. MARQUINA BARRIO, op. cit., 79-80.

50. Idem., 82 .

51. Vid. J. M. LABOA, op. cit., 73.

52. Vid. M. C. GARCÍA NIETO - J.M. DONEZAR, La España de Franco, 1939-1973 (Madrid, 1975), 57.

53. «Iglesia, Estado y Movimiento Nacional», 40-43.

54. Vid. M.C. GARCÍA NIETO. J.M. DONEZAR, op. cit., 57.

55. En cuanto a las numerosas manifestaciones públicas de este clima puede consultarse R.

GÓMEZ PÉREZ, Política y religión en el régimen de Franco (Barcelona, 1976).

56. Cfr. P. LOMBARDIA, op. cit., vol. I, 414.

57. Cfr. GUY HERMET, op. cit., vol. I, 414.

58. Cfr. GUY HERMET, op. cit., vol II, 44. 